\title{
Resurgence of Blind nasal intubation with Videolaryngoscopy as a guide for head maneuvers in the course of nasotracheal intubation in panfacial fracture patients with severely restricted mouth opening..
}

Kaushal Kumar, Preet Mohinder Singh

All India Institute of Medical Sciences, Dept. of Anaesthesiology, New Delhi, India

\section{Background}

Majority of the patients with pan facial fractures have severe limitation of mouth opening, particularly involving the zygoma and the angle of mandible.

$\checkmark$ Airway management is challenging in these cases, especially if mouth opening is less than $20 \mathrm{~mm}^{1}$.

- Awake nasal fiberoptic intubation is the standard technique of airway management in these patients posted for reduction of faciomaxillary and mandibular fractures.

$\checkmark$ However, in case of failed fiberoptic due to bleeding, particularly in panfacial trauma, the only option of securing the airway left is the surgical one.

- Blind nasal intubation can act as a bridge between a failed fiberscope attempt and a surgical airway, but it has become a dying art in present scenario ${ }^{2}$.

\section{Case Report}

- We describe airway management in a series of five cases of motorbike road traffic accident. All had panfacial fractures with severe restriction of mouth opening where fiberoptic intubation was not possible due to bleeding.

- Moreover, a videolaryngoscope blade could be just introduced into the oral cavity but manipulation with a Magill forceps was not possible.

- 2 cases had frontal bone fracture but non significant head trauma and none had any cervical injury.

$\checkmark$ All were posted for suturing of laceration and immediate ORIF.

\section{CASE I}

R Parasymphysis \#, L Angle of mandible \#

Airway examination: oral bleed +, IID-1.8cm, Intraoral haematoma, Intraoral laceration, laceration, left side of face abrasion, b/l condylar movement not palpable, deranged occlusion with open bite.

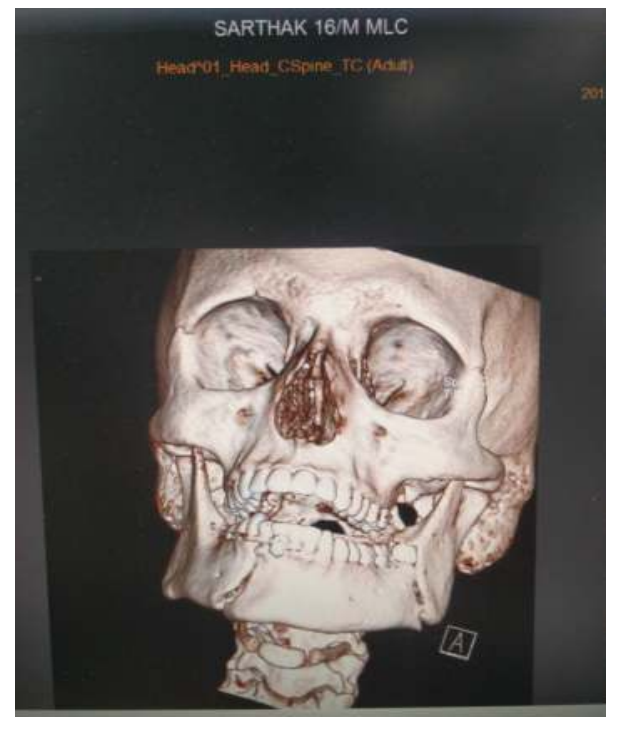

\section{CASE 2}

$\checkmark$ Compound \# of mandible, R Zygomatic arch

- Airway examination: oral bleed +, IID-2cm, Intraoral laceration, laceration $b / 1$ chin, $b / 1$ condylar movement faintly palpable, deranged occlusion and flattening of face.

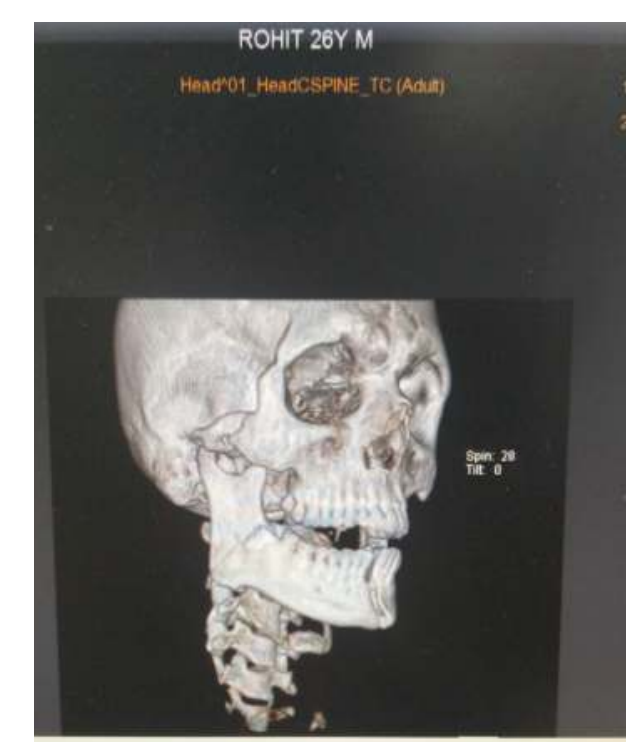

References

Hagberg CA. Benumof and Hagberg's airway management. 3rd ed. Philadelphia, Elsevier Inc. 2013, pP 403-4I.

Zhang J, Lamb A, Hung O, Hung C, Hung D. Blind nasal intubation: teaching a dying art. Can J Anaesth 2014; 61: 1055-6.
CASE 3

- L Mandibular parasymphysis \#, B/L Zygomatic arch \#, L. Zygoma\#, B/L Nasomaxillary Buttress\#, L FZ\#

Airway examination: oral and nasal bleed + , IID- $1.8 \mathrm{~cm}$, laceration $\mathrm{b} / 1$ cheek \& chin, L condylar movement faintly palpable.

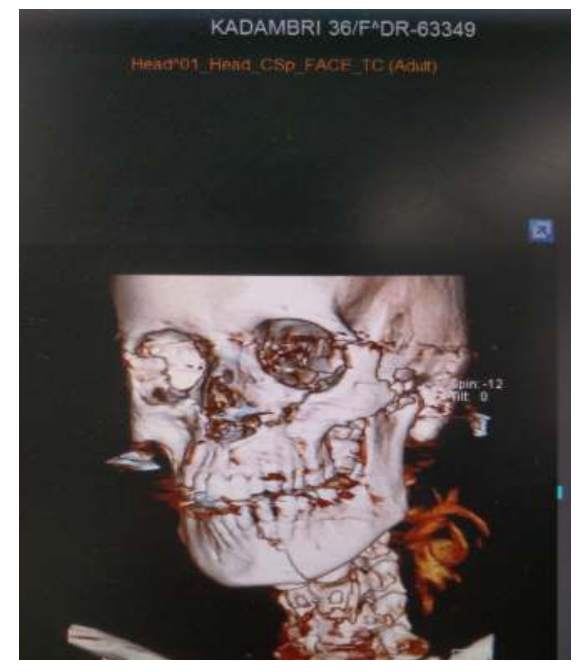

\section{CASE 4}

$\checkmark$ L ZMC \#, LEFORT I, Floor of Orbit \#, Sub condyle of Mandible \#, R Para median split

- Airway examination: oral and nasal bleed +, IID- $1.7 \mathrm{~cm}$, laceration L cheek, L Periorbital ecchymosis, b/l condylar movement not palpable, flattening of Left side of face, Deranged occlusion with open bite.

\section{CASE 5}

R. LEFORT II \#, L. FZ \#, B/L Infraorbita rim \#, Symphysis \#, R NOE \#

Airway examination: oral and nasal bleed + , IID- $1.8 \mathrm{~cm}$, Periorbital ecchymosis, Deranged occlusion.
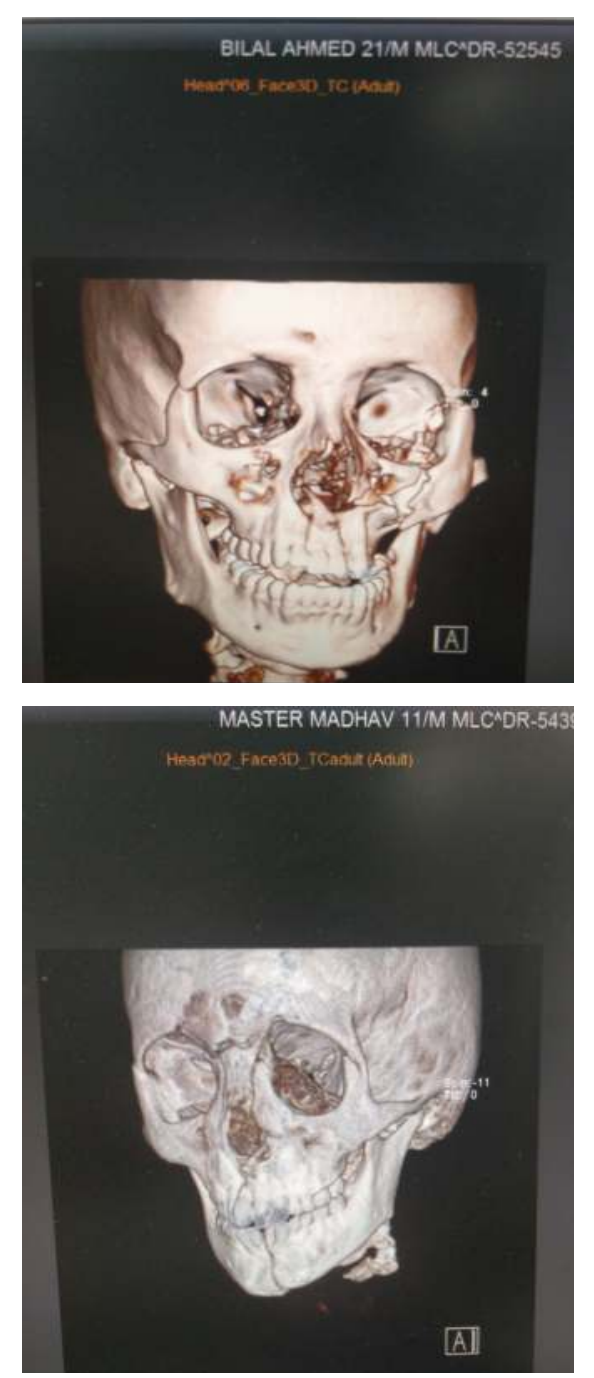

In first two cases, bleeding from oral cavity was moderate and needed oral suturing and Rest three had mild oozing.

- Bleeding with restricted mouth opening had made fiberoptic intubation improbable and preparation for surgical airway was being done.

In all the cases, it was possible to introduce the slim Macintosh type of C-Mac blade size 3 and in last one size 2 (maximum height 14 $\mathrm{mm}$ ), but any maneuvering with Magill forceps was not possible

$\checkmark$ Macintosh-shaped C-Mac videolaryngoscope showed the laryngeal view and the head maneuvers were done similar to the blind nasal intubation technique to guide the endotracheal tube past the vocal cords via the nasal route and the airway was secured.

\section{Discussion}

- Head maneuvering similar to the blind nasal technique was complemented with the videolaryngoscope and the airway was secured with much more ease than the blind nasal intubation due to objective means of guiding the maneuvers.

- This technique can serve as bridge between failed intubation and a surgical airway.

It could replace the standard nasal fiberoptic technique as plan A of airway management with patients of panfacial trauma with high risk of bleeding.

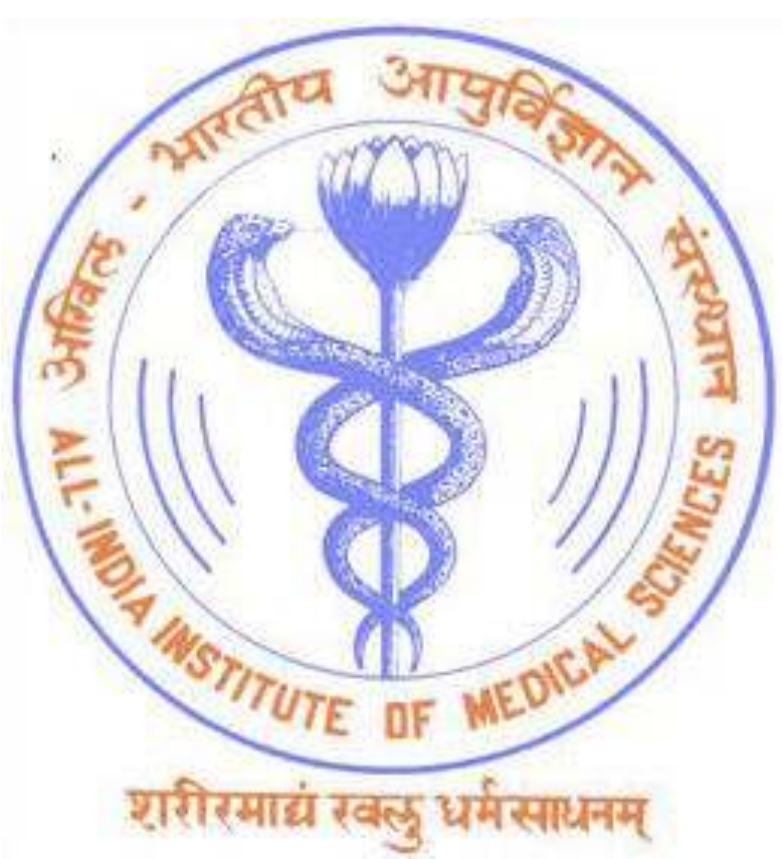

